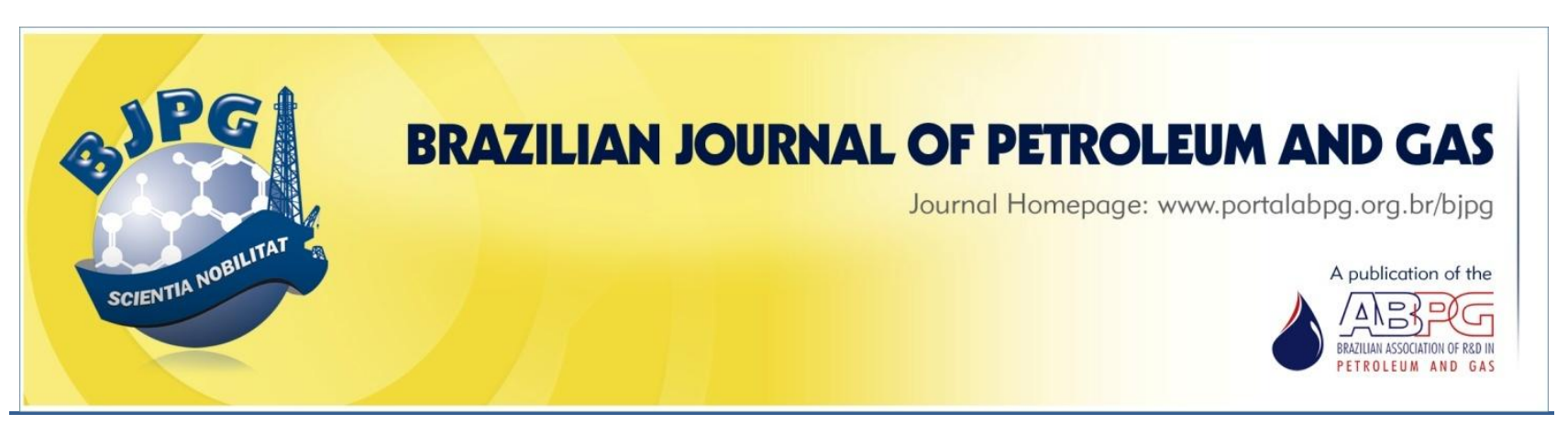

\title{
EVALUATION OF THE LUBRICATION OF ETHYL OLEATE AND ETHYL OCTANOATE AS GASOLINE ADDITIVE
}

\author{
${ }^{\text {a }}$ Sena, S. R. C. ${ }^{1}$; ${ }^{\text {a }}$ Barros Neto, E. L.; ${ }^{\text {a }}$ Pereira, C. G. \\ ${ }^{\text {a }}$ Federal University of Rio Grande do Norte, Department of Chemical Engineering, Natal - RN - Brazil
}

Received: 02.01.2019 / Revised: 10.04.2019 / Accepted: 08.05.2019 / Published on line: 08.10.2019

\begin{abstract}
The present study assesses the effects of ethyl octanoate and ethyl oleate on the gasoline lubricity. Samples of gasoline fuel were prepared with different amounts of esters $(0 \%, 2.5 \%, 5 \%, 10 \%$, and $15 \%)$ and then evaluated. The lubricity tests were carried out using a High Frequency Reciprocating Test Rig (HFRR) equipment. The Wear Scar Diameter (WSD) values decreased as ester proportions increased in the samples. The percentage of lubricant film presented values above $85 \%$ for formulations with $10 \%$ and $15 \%$ ester concentration. Coefficient of friction values showed a similar behavior, they decreased as the esters fractions have increased. Results demonstrate that the esters when added to gasoline can improve the fuel lubricity.
\end{abstract}

\section{KEYWORDS}

lubricity; ethyl oleate; ethyl octanoate; gasoline; fuels

\footnotetext{
${ }^{1}$ To whom all correspondence should be addressed.

Address: Federal University of Rio Grande do Norte, Department of Chemical Engineering, Graduate Studies Program in Chemical Engineering, University Campus, Lagoa Nova, Natal RN, Brazil.

ZIP Code: 59078-970 | Phone number: +55 84 99678-8014 | e-mail: suzararayanne@hotmail.com doi:10.5419/bjpg2019-0011
} 


\section{INTRODUCTION}

Considering that the increase of greenhouse gas emissions has become a major environmental issue, some changes have been imposed by governments to minimize such harmful side-effect of the burning of fossil fuels. Also, these strict environmental legislations have imposed the reduction of the concentration of several lubricant additives that could potentially contribute to the worsening of this scenario. As a consequence, the quality of fuel lubricants has decreased, compromising, for example, the components of internal combustion engines (Hu et al. 2017; Knothe et al. 2005; Muñoz et al., 2011). The role of a lubricant is to avoid the direct contact between surfaces that are in relative mutual movement, reducing friction and abrasion. Besides this its primary function, lubricants are also necessary to remove impurities and protect metal surfaces against corrosion (Stepina \& Vesely, 1992).

Arkoudeas et al. (2014) have reported on the need of intensifying research that addresses fuel lubricity, such as the gasoline one. This fuel can be consumed in its "purest" form or combined with a n ethyl alcohol. The latter option has risen as an alternative to reduce the dependence on the consumption of fossil fuels. The use of ethyl alcohol has been encouraged for it presents an accessible price, it is extracted from a renewable source, and its combustion releases less pollutants when compared to fossil fuel ones. Nevertheless, the use of ethyl alcohol can present some disadvantages, as mentioned by Rovai's study (2005). Rovai conducted lubricity measurements and verified that, when ethyl alcohol and gasoline are combined, there is a decrease in lubricity of the mixture as the proportion of alcohol increases. The addition of ethyl alcohol in diesel has shown the same effect, it decreased mixture lubricity and damaged fuel pumps, as stated by Li et al. (2005).

Thus, recent studies of lubricant systems have presented promising results in the area of minimization of energetic losses in combustion engines. Muñoz et al. (2011), in their research, evaluated the biodiesel obtained from the waste of vegetable oil as an additive to diesel fuel with low concentration in sulfur that could be used by vehicle engines. The result was a new fuel with high lubrication features. Lab-scale experiments were carried out using a vehicle engine fed with blends of diesel fuel free of traditional additives and biodiesel. As a result, the performance curves of the engine were very similar to the ones traced using only diesel fuel. In addition, pollutant emissions decreased substantially once biodiesel was combined with "pure" diesel, except for samples with nitrogen oxides. Arkoudeas et al. (2014) developed a study about lubricity and the effects of some physicochemical properties of three types of commercial gasoline, which had octane ratings of 95,96 , and 98 RON. They have shown that lubrication properties of the three types of gasoline were worse than the ones found for diesel fuels. The characteristics and the physicochemical properties from the different types of gasoline were affected in different degrees. The potassium concentration seemed to have a determinant role to obtain an effective protection against the abrasion, even when present in low amounts. Kuszewski et al. (2017) evaluated the lubricity of diesel and ethanol blends. According to their study, there were small variations in the lubrication levels of the analyzed samples. Moreover, blends containing up to $14 \%$ ethanol in diesel could meet lubrication standards. In another research, $\mathrm{Hu}$ et al. (2017) studied the effect of the lubricity of diesel fuels with low sulfur concentration added of tall oil fatty acid (TOFA) by measuring the wear scar diameter (WSD) and the coefficient of friction (COF). In this case, the additive has improved the lubrication levels significantly, and both WSD and COF were reduced significantly.

Typically, more attention is paid to the lubrication of diesel fuels than to the lubrication of gasoline ones. This happens because gasoline pumps are operated at high pressure conditions. In this context, there are few researches on gasoline lubrication and there is no standard test specifications set, while, in the case of diesel, there is a standard test in place to evaluate diesel lubrication (Fusco et al., 2005). Therefore, this study aims to assess the effect of oxygen additives such as ethyl octanoate and ethyl oleate on gasoline lubricity. For this purpose, the lubrication film formation, the COF and the WSD of the ball were considered. 


\section{MATERIALS AND METHODS}

\subsection{Sample preparation}

The esters were obtained through esterification reaction. This is the most common method to obtain esters by a reversible reaction between a carboxylic acid and an alcohol with water elimination. The reaction conditions were: molar ratio of $1: 3$ of fatty acid (octanoic acid synth, lot 17924 , oleic acid - synth, lot 188985) to ethanol (synth, lot 190231); $\mathrm{H}_{2} \mathrm{SO}_{4}$ (Sigma Aldrich, lot SZBE2260V) with $1 \%$ mass of fatty acid as reaction catalyzer; $80^{\circ} \mathrm{C}$, and $60 \mathrm{~min}$ reaction time. Once the reaction was finished, the products were submitted to an extraction protocol with solvent (water), a chemically activated extraction with a 0,01M sodium bicarbonate solution (Êxodo Cientifica, lot BS8763KA), an adsorption of water traces through the addition of anhydrous sodium sulfate (Dinâmica Química Contemporânea, lot 55937), and, finally, a filtration procedure (Nicolau et al., 2010).

The A type gasoline (i.e. free from ethanol) was used as a standard fuel and it was supplied by an oil refinery located in the Brazil.

\subsection{Lubricity analyses}

To analyze the lubricity, some blends of gasoline and ester were prepared considering ester concentrations on volume fractions of 0 , $2.5,5,10$, and $15 \%$ for each corresponding blend. The formulations were labeled in accordance with the volume fraction of ethyl oleate $(\mathrm{OL})$ or ethyl octanoate $(\mathrm{OC})$ in the blends such as OL-2.5, OL-5, OL-10, OL- 15, OC-2.5, OC-5, OC-10, and OC-15. The gasoline and each ester were individually analyzed. In this case, the samples were labeled as G-100 for only gasoline, OL-100 for ethyl oleate, and OC-100 for ethyl octanoate.

Lubricity tests were carried out in a high frequency reciprocating test rig (HFRR) equipment made by PCS Instruments. Initially, the tribological pair, ball and disk, and both AISI E-52100 steel had to be cleaned through processes of sanding and polishing by applying alumina (Arotec - 0.5 micron) as abrasive agent and, then, they had to be purified with acetone (Vetec, lot DCBB6413) in ultrasonic bath (Ultrasonic, 1440 plus) during 10 $\min$.
Table 1. Lubricity test conditions.

\begin{tabular}{lc}
\hline Temp. $\left({ }^{\circ} \mathrm{C}\right)$ (sample: ester) & 60 \\
Temp. $\left({ }^{\circ} \mathrm{C}\right)$ (sample: gasoline+ester) & 25 \\
Fuel volume $(\mathrm{mL})$ & $2.0 \pm 0.2$ \\
Length of course $(\mathrm{mm})$ & $1.00 \pm 0.02$ \\
Frequency of oscillation $(\mathrm{Hz})$ & $50 \pm 1$ \\
Applied load $(\mathrm{N})$ & $1.96 \pm 0.01$ \\
Duration of the test $(\mathrm{min})$ & $75.0 \pm 0.1$ \\
Number of cycles & 225000 \\
Slip distance $(\mathrm{m})$ & 450 \\
\hline
\end{tabular}

Experiment conditions followed ASTM D 607904 (2005) standard resolution, which states that, for samples composed by gasoline, the temperature must be decreased since it is recommended to fuels that are more volatile than diesel fuel. The parameters for the lubricity analyses are described in the Table 1.

In this method, a certain amount of sample is poured in the support of the disk and maintained at a specific temperature. The ball is submitted to an alternated slipping movement with amplitude and frequency previously set, while the interface with the disk is totally immersed in the fluid. All the analyses were made in duplicate and, before each analysis, the HFRR components that were in contact with the samples underwent cleaning procedures by immersions in ultrasonic bath with acetone for 10 minutes.

This analysis provides the coefficient of friction (COF) and the percentage of interfacial film along the time set to run the measurement. The wear scar diameter (WSD) was measured using an optical microscope (Meiji Techno, ML7000) coupled to the HFRR system, and it was, then, determined from the arithmetical mean of $(x)$ and (y) scar diameters of the ellipse. Figure 1 shows the mechanical unit of the HFRR system.

\section{RESULTS AND DISCUSSION}

\subsection{Wear Scar Diameter (WSD)}

One of the parameters to assess the lubricity is the WSD, which is determined from the scar scratched on the ball employed by the HFRR apparatus. Figure 2 shows the WSD of the balls for each blend that was analyzed. 


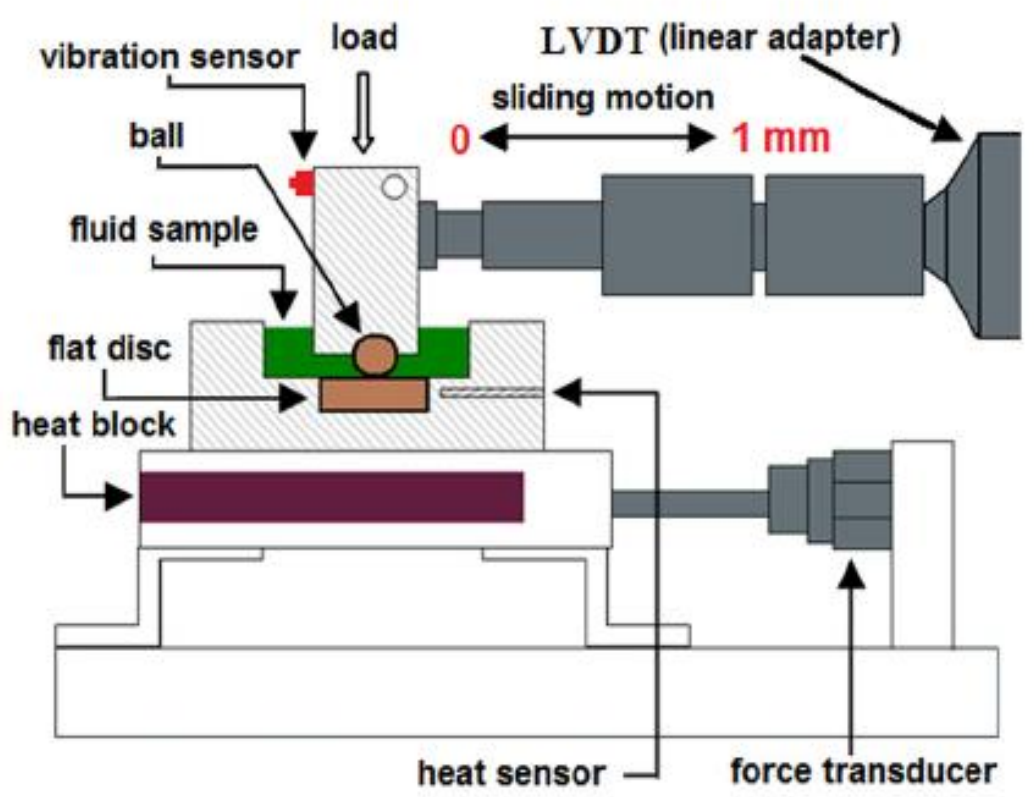

Figure 1. Schematic diagram of the test on the HFRR lubricity equipment (Farias, 2015).

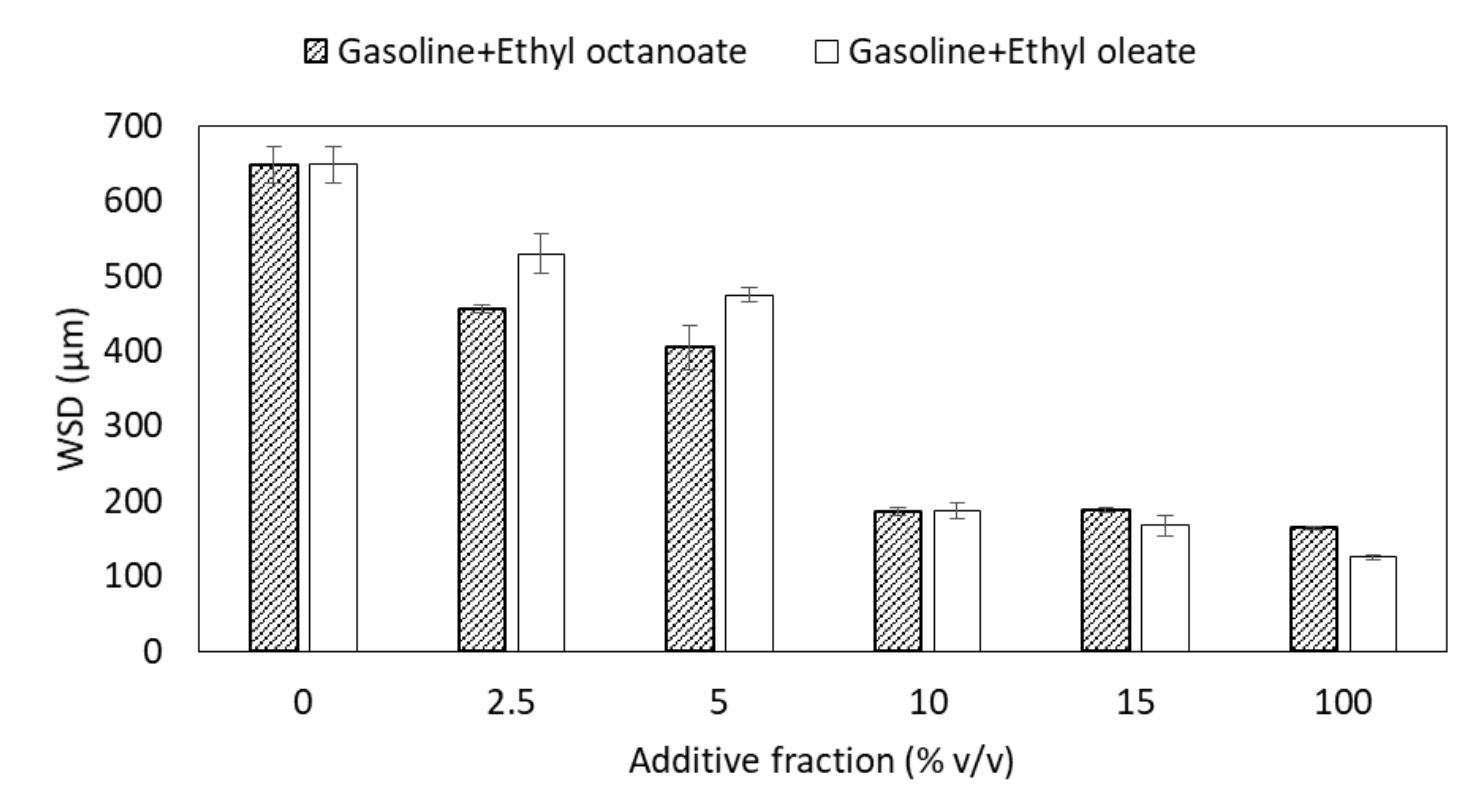

Figure 2. WSD (Wear Scar Diameter) formulations containing gasoline, ethyl oleate, and ethyl octanoate.

The WSD is associated with the degree of fuel lubricity. A small value of WSD means a better lubricity which guarantees the efficiency of the lubricant interfacial film of the fuel that separates disk and ball surfaces. The results have shown that after the gasoline was complemented with ethyl oleate and ethyl octanoate, there was a decrease of the scar as ester concentrations had increased in the blends. The gasoline sample presented a WSD value of $648 \mu \mathrm{m}$ while the sample with $15 \%$ of ethyl oleate presented a WSD of $167 \mu \mathrm{m}$. This means that the WSD had shrunk in $74 \%$. On the other hand, the sample with $15 \%$ of ethyl octanoate presented a WSD equivalent to $187 \mu \mathrm{m}$, corresponding to a reduction of $71 \%$ in relation to the standard fuel sample. According to international resolution ASTM D 975-10 (2005), the maximum WSD value allowed is $520 \mu \mathrm{m}$. Consequently, it is also possible to compare the results that were obtained for the blends containing $2.5 \%$ of oleate or octanoate and to deduce that they meet WSD specifications. 


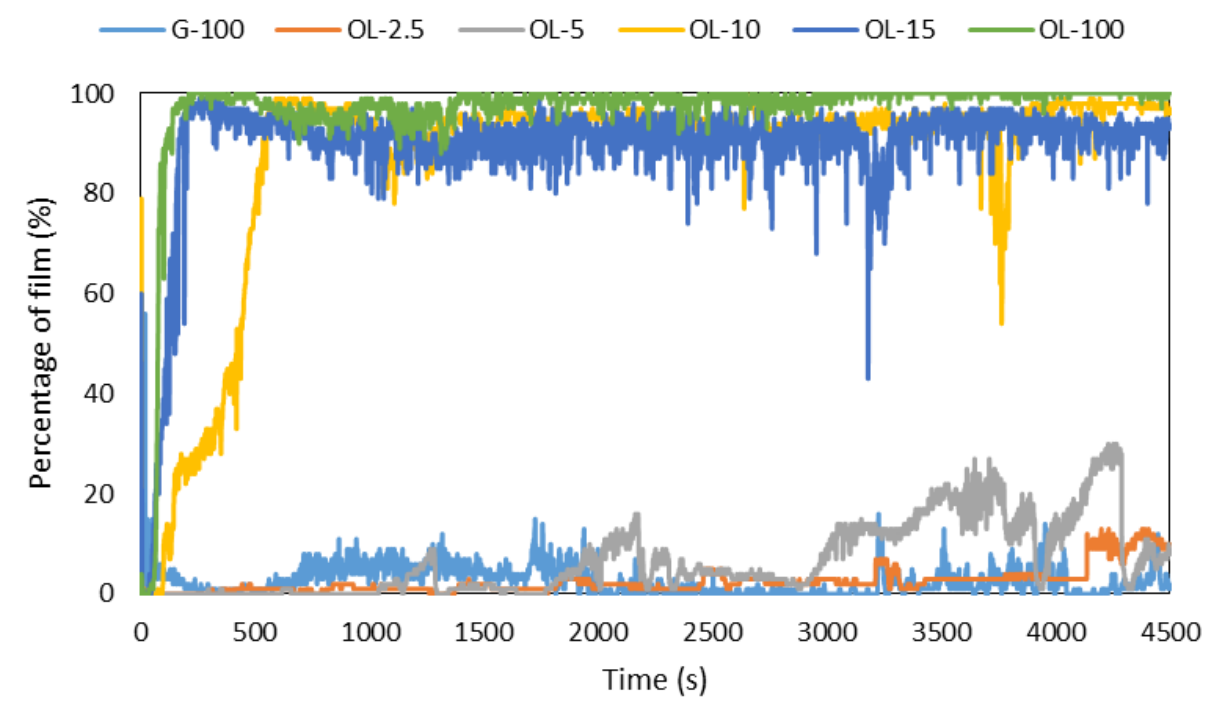

Figure 3. Lubricating film of the formulations containing gasoline and ethyl oleate.

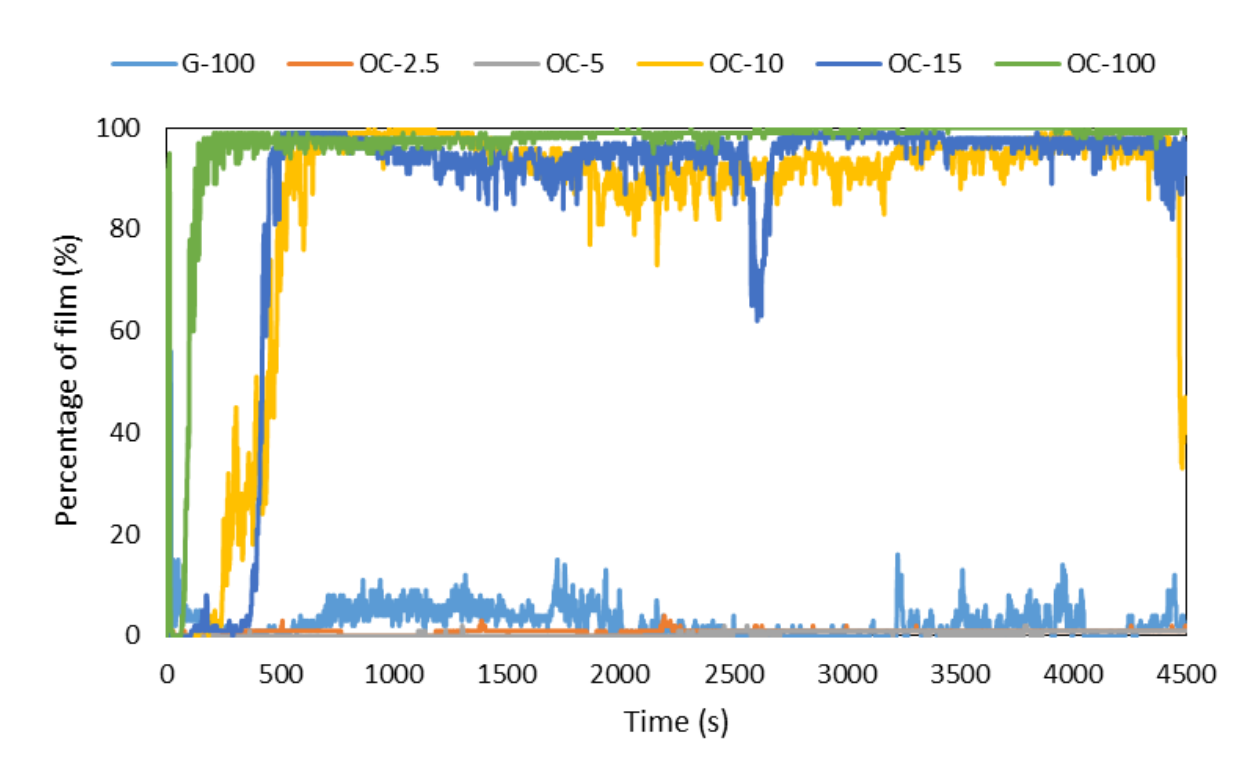

Figure 4. Lubricating film of the formulations containing gasoline and ethyl octanoate.

\subsection{Film formation and Coefficient of Friction (COF)}

The formation of the lubricant film and the Coefficient of Friction (COF) values for each analyzed blend are shown in Figures 3 to 6 .

Figures 3 and 4 show a film formation for ethyl oleate and ethyl octanoate samples, attaining high values in the initial seconds of the tribological test. The lubricant film of the ethyl oleate sample was $97 \%$ while the one of the ethyl octanoate sample was $95 \%$. For the studied formulations, it can be inferred that the increase of ester concentrations promoted a better formation of the lubricant film, especially in samples composed by $10 \%$ and $15 \%$ volume of ester, resulting in an average lubricating film of $85 \%$ for OC-10, $87 \%$ for OC-15, $87 \%$ for OL-10, and $90 \%$ for OL-15.

The lubricant film of the gasoline sample was basically null along the time set to run the measurement. Such result is in agreement with the high COF value presented by this sample. A high COF value normally indicates a poor lubrication. After gasoline additivation with the esters, COF values have decreased as esters 


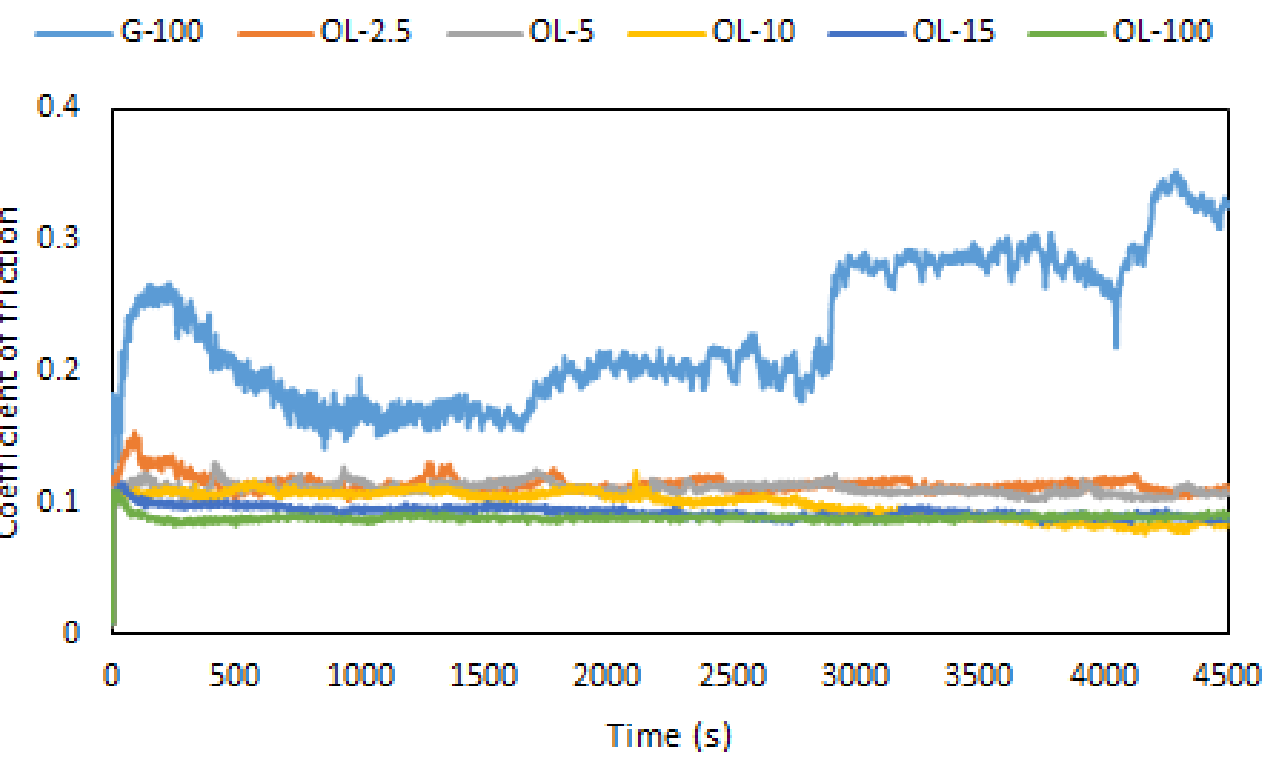

Figure 5. Coefficient of friction of formulations containing gasoline and ethyl oleate.

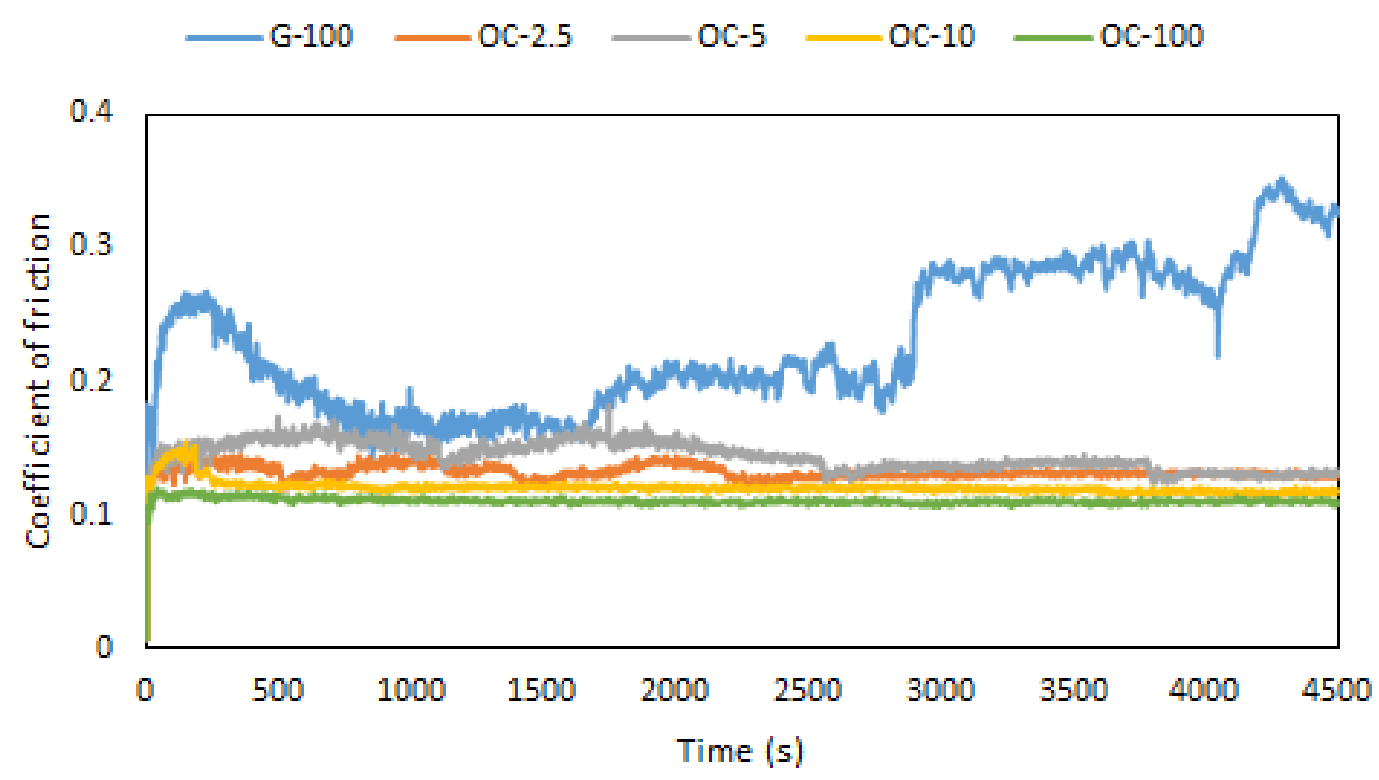

Figure 6. Coefficient of friction of formulations containing gasoline and ethyl octanoate.

concentrations have increased, as it can be seen in Figures 5 and 6 . A COF value of 0.093 was obtained for the blend with $15 \%$ on volume of ethyl oleate while a COF of 0.120 was found for the blend with $15 \%$ volume of ethyl octanoate. These COF values can be translated as reductions of $59 \%$ and $48 \%$, respectively, when compared to the "pure" gasoline COF value.

The analyses of both parameters, lubricant film formation and COF, have displayed good lubricant characteristic after the addition of esters to the gasoline. Gasoline samples blended with 15\% ethyl oleate and $15 \%$ ethyl octanoate presented the best lubricant characteristics. The presence of oxygen in the ester molecules induces a polarity phenomenon, which can explain the better lubricity results when esters are added to the gasoline. This result is similar to the ones found in other related studies (Farias et al., 2014; Hazrat et al., 2015), where a better lubricity is observed after biodiesel is combined with diesel fuel. These chemical polar species adsorb on the friction surface forming a protective film, preventing metal on metal contact and abrasion (Knothe et al., 2005; Nicolau et al., 2014). 


\section{CONCLUSIONS}

This study evaluated the influence of ethyl oleate and ethyl octanoate on gasoline lubricity. The results found herein have shown that gasoline additivation with esters can reduce WSD, indicating an improvement of the degree of gasoline lubricity. The lowest values of WSD were obtained from the samples with $15 \%$ of ethyl oleate $(167 \mu \mathrm{m})$ and $15 \%$ of ethyl octanoate $(187 \mu \mathrm{m})$. With respect to film formation, the results demonstrated that the addition of 10 and $15 \%$ of ethyl oleate favored high percentages of film formation. The sample containing $15 \%$ of this ester presented an even more considerable and stable lubricant film, a value of $90 \%$. In the case of the gasoline combined with the ethyl octanoate, the sample containing $10 \%$ and $15 \%$ of this ester presented a more significant lubricant film formation, a value of $85 \%$ and $87 \%$, respectively. The additivation of the gasoline with the esters has also decreased the COF, as ester concentrations have increased. Comparing the blended samples which had 15\% of ethyl oleate and $15 \%$ of ethyl octanoate with the standard fuel sample, COF values have experienced a decrease in 59 and $48 \%$, respectively. Overall, the correlation of these results point out that gasoline containing esters as additives can improve fuel lubrication and resistance against the abrasion.

\section{ACKNOWLEDGMENTS}

The authors recognize Brazilian National Research Council (CNPq) and Federal University of Rio Grande do Norte (UFRN), especially the Graduate Program in Chemical Engineering, for their financial support.

\section{REFERENCES}

Arkoudeas, P.; Karonis, D.; Zannikos, F.; Lois, E. Lubricity assessment of gasoline fuels. Fuel Processing Technology, v. 122, p. 107-119, 2014. https://doi.org/10.1016/i.fuproc.2014.01.008

ASTM International. ASTM D 6079-04 Standard test method for evaluating lubricity of diesel fuels by the high-frequency reciprocating rig (HFRR). West Conshohocken: ASTM International; 2004.
ASTM International. ASTM D 975-10 Standard specification for diesel fuel oils. West Conshohocken: ASTM International; 2005.

Farias, A. C. M.; Medeiros, J. T. N.; Alves, S. M. Micro and nanometric wear evaluation of metal discs used on determination of biodiesel fuel lubricity. Materials Research, v. 17, p. 89-99, 2014.

https://doi.org/10.1590/S1516-14392014005000101

Farias, A. C. M.; Medeiros, A. A. S.; Júnior, J. J. O.; Alves, S. M. Correlation between fuel lubricity and vibration signals obtained in ball-disc analysis using Fourier transform. Materials Research, v. 18, p. 210-219, 2015. https://doi.org/10.1590/1516-1439.368414

Fusco, F.; Katsuki, D.; Sinatora, A. Wear and corrosion evaluation of electric fuel pumps with ethanol/gasoline blends. SAE paper, p. 356-364, 2005.

Hazrat, M. A.; Rasul, M. G.; Khan, M. M. K. Lubricity improvement of the ultra-low sulfur diesel fuel with the biodiesel. Energy Procedia, v. 75, p.111-117, 2015.

https://doi.org/10.1016/i.egypro.2015.07.619

$\mathrm{Hu}$, Z.; Zhang, L.; Li, Y. Investigation of tall oil fatty acid as antiwear agent to improve the lubricity of ultra-low sulfur diesels. Tribology International, v. 114, p. 57-64, 2017. https://doi.org/10.1016/i.triboint.2017.04.016

Knothe, G.; Steidley, K. R. Lubricity of components of biodiesel and petrodiesel. The origin of biodiesel lubricity. Energy \& Fuels, v. 19, p. 1192-1200, 2005. https://doi.org/10.1021/ef049684c

Kuszewski, H.; Jaworski, A.; Ustrzycki, A. Lubricity of ethanol-diesel blends - Study with the HFRR method. Fuel, v. 208, p. 491-498, 2017. https://doi.org/10.1016/i.fuel.2017.07.046

Li, D.; Zhen, H.; Xingcai, L.; Wu-Gao, Z.; JianGuang, Y. Physico-chemical properties of ethanol-diesel blend fuel and its effect on performance and emissions of diesel engines. Renewable Energy, v. 30, p. 967-976, 2005. https://doi.org/10.1016/i.renene.2004.07.010

Muñoz, M.; Moreno, F.; Monné, C.; Morea, J.; Terradillos, J. Biodiesel improves lubricity of new low sulphur diesel fuels. Renewable Energy, v. 36, p. 2918-2924, 2011.

https://doi.org/10.1016/j.renene.2011.04.007 
Nicolau, A.; Lutckmeier, C. V.; Samios, D.; Gutterres, M.; Piatnick, C. M. S. The relation between lubricity and electrical properties of low sulfur diesel and diesel/biodiesel blends. Fuel, v. 117, p. 26-32, 2014.

https://doi.org/10.1016/j.fuel.2013.09.026

Nicolau, A.; Mariath, R. M.; Martini, E. A.; Martini, D. S.; Samios, D. The polymerization products of epoxidized oleic acid and epoxidized methyl oleate with cis-1,2cyclohexanedicarboxylic anhydride and triethylamine as the initiator: Chemical structures, thermal and electrical properties. Materials Science and Engineering, v. 30, p. 951-962, 2010. https://doi.org/10.1016/j.msec.2010.04.014
Rovai, F. F. Desgaste e corrosão de bombas de combustível com misturas de álcool e gasohol. 117f. Dissertação de Mestrado. Escola Politécnica da Universidade de São Paulo, São Paulo, 2005. (In Portuguese).

Stepina, V.; Vesely, V. Lubricants and Special Fluids. Tribology series 23. Amsterdam: Elsevier, 1992. 